\title{
Glucose-dependent glucose transporter 1 expression and its impact on viability of thyroid cancer cells
}

\author{
PAWEŁ JÓŹWIAK, ANNA KRZEŚLAK, MAGDALENA BRYŚ and ANNA LIPIŃSKA \\ Department of Cytobiochemistry, Faculty of Biology and Environmental Protection, University of Lodz, 90-236 Lodz, Poland
}

Received September 18, 2014; Accepted November 27, 2014

DOI: $10.3892 /$ or.2014.3673

\begin{abstract}
Cancer cells exhibit an altered metabolism characterized by enhanced glycolysis and glucose consumption. In glucose-addicted cancer cells upregulation of glucose transport across the plasma membrane is mediated by a family of facilitated glucose transporter proteins, particularly glucose transporter 1 (GLUT1). The aim of the present study was to investigate the impact of GLUT1 expression on glucose uptake and viability of FTC-133 and 8305c thyroid cancer cells growing in hypoglycemic, normoglycemic and hyperglycemic conditions. The results showed that the total expression of GLUT1 was higher in the two cell types growing in low glucose compared to cells growing in normoglycemia or hyperglycemia and this was correlated with AKT Ser473 phosphorylation but not with the expression of hypoxia inducible factor $\alpha$ (HIF $1 \alpha)$. However, the membrane expression of GLUT1 was correlated with HIF1 $\alpha$ expression. HIF1 $\alpha$ expression was positively correlated with the glucose concentration in FTC-133 cells, whereas this expression was inversely correlated in 8305 c cells. Glucose uptake was dependent on the membrane level of GLUT1 but not total GLUT1 expression. Downregulation of GLUT1 expression by RNAi in FTC-133 cells caused a reduction in glucose uptake but did not significantly affect cell viability. In the case of 8305c cells showing low endogenous GLUT1 expression and lack of HIF1 $\alpha$ expression in normoxic conditions GLUT1 RNAi impacted cell viability. These data suggested that GLUT1 may be part of an AKT1-dependent mechanism allowing cells to survive in low levels of glucose. Glucose concentration inversely affected HIF1 $\alpha$ expression and the level of GLUT1 in membrane as well as glucose uptake in FTC-133 and 8305c cells. The extent of GLUT1 impact on cell viability was also cell-type-dependent.
\end{abstract}

Correspondence to: Dr Anna Krześlak, Department of Cytobiochemistry, Faculty of Biology and Environmental Protection, University of Lodz, Pomorska 141/143, 90-236 Lodz, Poland

E-mail:krzeslak@biol.uni.lodz.pl

Key words: GLUT1, HIF1 $\alpha$, AKT1, glucose uptake, cell viability

\section{Introduction}

Cancer cells exhibit an altered metabolism characterized by high rates of glucose consumption and glycolysis $(1,2)$. Glucose-addicted cancer cells were found to be very sensitive to glucose concentration levels. Glucose deprivation may induce growth inhibition and death of cancer cells (3-5). Enhanced glucose requirement of cancer cells is associated with increased glucose transport across the plasma membrane, which is mediated by a family of facilitated glucose transporter proteins, known as glucose transporters (GLUTs) (6-9). In mammals, 14 GLUTs have been identified and each possesses a different affinity for glucose and other hexoses $(9,10)$. The results of recent studies have demonstrated that the expression of glucose transporters, particularly GLUT1, is increased in a variety of malignancies including breast, endometrial, head and neck, salivary gland, colorectal, gastric, lung and thyroid cancers (11-16). The overexpression of GLUT1 is often associated with enhanced invasive potential and poor prognosis. GLUT1 expression has also been shown to correlate with the level of tumor hypoxia. Hypoxia inducible factor (HIF) is responsible for the transcription activation of a number of glycolytic genes as well as GLUT1 (17).

Results of epidemiological studies indicate that obesity and diabetes are associated with an increased risk of several types of cancer, including colonic, esophageal, gastric, liver, pancreatic, kidney, endometrial, breast, and bladder cancer (18-23). Chronic high blood glucose level seems to be a key factor of cancer progression (24). However, whether diabetes or hyperglycemia increases the risk of thyroid cancer has not been extensively studied. The relationship between chronic high glucose level and thyroid cancer are not fully elucidated and the results of available studies are controversial (25).

The aim of the present study was to investigate the relationship between the expression of GLUT1 and glucose uptake as well as viability of thyroid cancer cells growing in hypoglycemia, normoglycemia and hyperglycemia conditions.

\section{Materials and methods}

Reagents and antibodies. Chemicals were obtained from Sigma-Aldrich (St. Louis, MO, USA) except as noted. Cell culture reagents and materials were purchased from Invitrogen (Carlsbad, CA, USA), Cytogen (Sinn, Germany) and Corning Inc. (Corning, NY, USA). The antibodies from 
Santa Cruz Biotechnology, Inc., (Santa Cruz, CA, USA) used were: mouse monoclonal anti-GLUT3, rabbit polyclonal anti-HIF1 $\alpha$, mouse monoclonal anti- $\beta$-actin, goat polyclonal anti-rabbit IgG-HRP and goat polyclonal anti-mouse IgG-HRP. The polyclonal rabbit anti-GLUT1 antibodies were from Abcam (Cambridge, UK). Mouse monoclonal anti-AKT1 and rabbit polyclonal anti-phospho-AKT1 (Ser473) were from Cell Signaling Technology, Inc. (Beverly, MA, USA).

Cell culture and treatment. FTC-133 (follicular) and 8305c (anaplastic) thyroid cancer cells were obtained from the European Collection of Cell Cultures (ECACC) (Wiltshire, UK). The cells were grown in Dulbecco's minimal essential medium (DMEM) supplemented with $2 \mathrm{mM}$ glutamine and $10 \%$ fetal bovine serum (FBS) in a humidified atmosphere containing $5 \% \mathrm{CO}_{2}$ at $37^{\circ} \mathrm{C}$. Hypoxic treatment conditions were based on normal oxygen conditions with the chemical hypoxic agent cobalt chloride $\left(\mathrm{CoCl}_{2}\right)$ being added to the medium. $\mathrm{CoCl}_{2}$ was used at a final concentration of $100 \mu \mathrm{M}$. To assess the impact of hypoglycemia, normoglycemia and hyperglycemia on cell viability and glucose uptake cells were grown for $48 \mathrm{~h}$ in medium containing 2, 5 or $25 \mathrm{mM}$ glucose, respectively.

Silencing of GLUT1. For reduction of GLUT1 expression Silencer Select siRNA was used (ID: s12926; Ambion Life Technologies, Carlsbad, CA, USA). In the negative control experiments scrambled non-silencing siRNA was used (Silencer Select Negative Control no. 1; Ambion, Life Technologies, Carlsbad, CA, USA). Transfections were carried out using Lipofectamine ${ }^{\mathrm{TM}}$ RNAiMAX (Invitrogen) following the manufacturer's instructions. The cells were treated with $30 \mathrm{nM}$ of siRNAs, and the effect of interference was assessed after 48 or $72 \mathrm{~h}$. Cell lysates were collected and reverse transcription PCR (RT-PCR) and western blotting were performed to assess the effectiveness of RNAi.

$R T-P C R$. RNA was isolated from the FTC-133 and $8305 \mathrm{c}$ cells using the total RNA isolation kit (A\&A Biotechnology, Gdynia, Poland) according to the manufacturer's instructions. First-strand cDNAs were obtained by the reverse transcription of $1 \mu \mathrm{g}$ of total RNA using a High-Capacity cDNA Reverse Transcription kit (Applied Biosystems, Foster City, CA, USA) following the manufacturer's instructions. Real-time amplification of the cDNA was performed using a TaqMan ${ }^{\circledast}$ Gene Expression Assay (Applied Biosystems). The fluorogenic, FAM-labeled probes and the sequence-specific primers for $S L C 2 A l$ (gene coding GLUT1) and the internal control glyceraldehyde-3-phosphate dehydrogenase $(G A P D H)$ were obtained as inventoried assays (Hs00982681 and Hs99999905, respectively). GLUT mRNA levels normalized to GAPDH mRNA levels were calculated using the formula: $2^{-\mathrm{ACt}}$, where $\Delta \mathrm{Ct}=\mathrm{Ct}_{\mathrm{GLUT1}}-\mathrm{Ct}_{\mathrm{GAPDH}}$. Relative amounts of mRNA in GLUT1 siRNA-treated cells are indicated as a percentage of the amount of mRNA in control cells.

Isolation of the plasma membrane proteins. Surface proteins were isolated from cells by affinity chromatography on streptavidin-agarose after plasma membrane protein biotinylation.
The cells grown on the 100-mm Petri dishes were washed twice with ice-cold phosphate-buffered saline (PBS) and incubated with $250 \mu \mathrm{g} / \mathrm{ml} N$-hydroxysucinimide-long-chain-biotin (NHS-LC-biotin; Thermo Scientific, Waltham, MA, USA) in PBS for $1 \mathrm{~h}$ at $4^{\circ} \mathrm{C}$. To stop the biotinylation, monolayers were rinsed three times with ice-cold PBS containing $15 \mathrm{mM}$ glycine. The cells were then scraped on ice in PBS, the number of cells were counted and the same amount of cells $\left(10^{7}\right)$ was added to each tube and centrifuged at $200 \mathrm{x}$ g for $5 \mathrm{~min}$. Cell pellets were lysed with RIPA buffer $(0.15 \mathrm{M} \mathrm{NaCl}, 50 \mathrm{mM}$ HEPES pH 7.1, $1 \%$ Triton X-100, 0.5\% DOC, $0.1 \%$ SDS, $10 \mathrm{mM}$ EDTA, $2 \mathrm{mM}$ PMSF) and centrifuged at 9,000 $\mathrm{x}$ g for $3 \mathrm{~min}$. The supernatants were transferred to new vials with $100 \mu 1$ streptavidin-agarose beads (Sigma-Aldrich, St. Louis, MO, USA) and gently mixed overnight at $4^{\circ} \mathrm{C}$. After centrifugation, the supernatants were removed, the beads were washed five times with $1 \mathrm{ml} 0.15 \mathrm{M} \mathrm{NaCl}, 10 \mathrm{mM}$ Tris- $\mathrm{HCl} \mathrm{pH} 7.0$ containing $2 \mathrm{mM}$ PMSF, and once again with PBS. The final pellet was resuspended in $200 \mu \mathrm{l}$ Laemmli's buffer (1.2-fold concentration without mercaptoethanol) and incubated for $30 \mathrm{~min}$ at $65^{\circ} \mathrm{C}$. The supernatants containing solubilized cell surface proteins were separated from the beads by centrifugation, collected and run on SDS-PAGE.

Western blotting. Proteins of the cell lysates and cell surface protein samples were resolved by $10 \%$ SDS-PAGE and electroblotted onto Immobilon-P transfer membranes. The blots were incubated with primary antibodies for $2 \mathrm{~h}$ in room temperature. After washing three times with Tris-buffered saline (TBS) the blots were incubated for $1 \mathrm{~h}$ with goat antimouse or anti-rabbit secondary antibodies conjugated with horseradish peroxidase. Proteins were visualized on X-ray film by an enhanced chemiluminescence method. For loading control, the blots were reprobed with anti- $\beta$-actin antibody following a stripping protocol. Gel-Pro Analyzer software version 3.0 (Media Cybernetics, Inc., Bethesda, MD, USA) was used for the densitometric analysis of the protein bands.

Cell viability assay. Cell viability was assessed using the MTT assay. Cells were plated in 96-well plates at a density of 10,000 or 15,000 for FTC-133 and 8305c, respectively and cultivated for $24 \mathrm{~h}$ in standard conditions. The medium was replaced with a new medium and the cells were appropriately treated with different glucose concentrations, $\mathrm{CoCl}_{2}$ and siRNA. Twenty microliters of $0.05 \%$ [3-(4,5-dimethylthiazol2-yl)-2,5 diphenyltetrazolium bromide MTT] (Sigma) in PBS was added to each well and the cells were incubated for $3 \mathrm{~h}$ in $37^{\circ} \mathrm{C}$. The medium was then removed and $50 \mu \mathrm{l}$ of DMSO was added. Absorbance of the formazan product was measured at $590 \mathrm{~nm}$ by a microtiter plate reader (Bio-Rad, Hercules, CA, USA) with a blank (medium alone) as the background control.

2-NBDG assay. To analyze glucose uptake the fluorescent glucose analog, 2-(N-[7-nitrobenz-2-oxa-1,3-diazol-4-yl] amino)-2-deoxyglucose (2-NBDG), which allows for direct quantification of glucose incorporation in living cells by flow cytometry, was used (26). Cells grown for $48 \mathrm{~h}$ in medium containing 2,5 or $25 \mathrm{mM}$ glucose were washed with Dulbecco's phosphate-buffered saline (DPBS) and medium containing $0.25 \mathrm{mM}$ glucose and $300 \mu \mathrm{M}$ 2-NBDG was added. After 
A

FTC-133

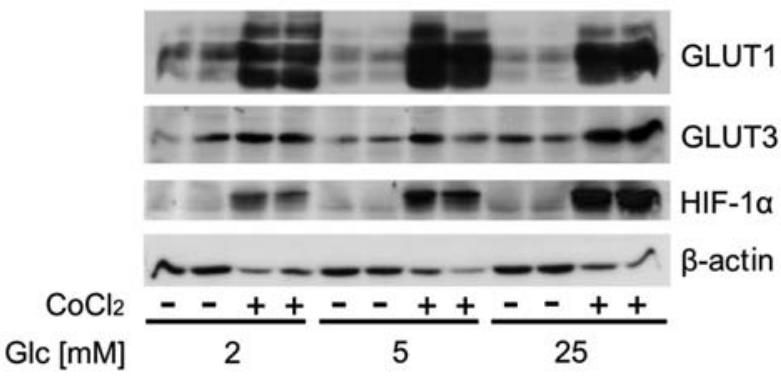

B

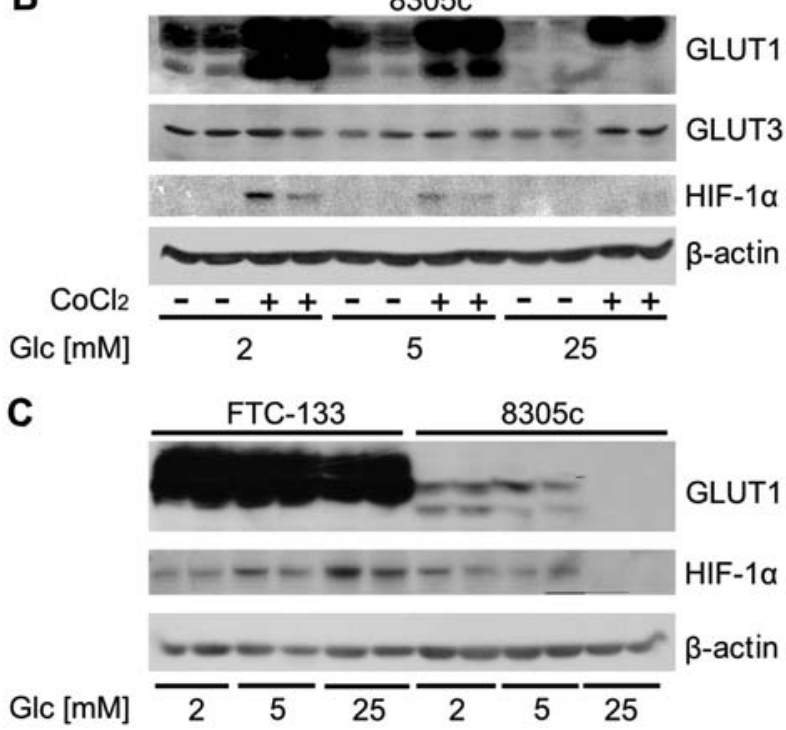

Figure 1. Effect of hypoglycemia, normoglycemia and hyperglycemia on the expression of GLUT1, GLUT3 and HIF1 $\alpha$ in normoxic and hypoxic conditions in FTC-133 (A) and 8305c cells (B). Differences in GLUT1 and HIF1o expression levels in FTC-133 and 8305c cells (C). The immunodetection of GLUT1 and HIF1 $\alpha$ in lysates from the cells treated with $\mathrm{CoCl}_{2}$ was performed on one blot to show the expression differences. GLUT1, glucose transporter 1; HIF $1 \alpha$, hypoxia inducible factor $\alpha$.

40 min incubation the cells were washed twice with DPBS, trypsinized, centrifuged and resuspended in DPBS. In the flow cytometer, optical filters were set up such that 2-NBDG was measured using the green fluorescence $(520 \mathrm{~nm})$ channel FL1. The results were collected as the median fluorescent signal from a population of $10^{4}$ cells.

Statistical analysis. Experimental data are presented as the means \pm SD. For comparison of groups, the Student's t-test was used. $\mathrm{P}<0.05$ was considered to indicate a statistically significant result.

\section{Results}

Glucose-dependent HIFl $\alpha$ and GLUT1 expression in normoxic and hypoxic conditions. To determine whether the glucose concentration affected the level of GLUT1 expression FTC-133 and $8503 \mathrm{c}$ cells were grown for $48 \mathrm{~h}$ in medium containing 2,5 or $25 \mathrm{mM}$ glucose, resembling hypoglycemic, normoglycemic and hyperglycemic conditions. The cells were or were not treated for $48 \mathrm{~h}$ with $100 \mu \mathrm{M}$ cobalt chloride to induce hypoxic conditions. In cell lysates the

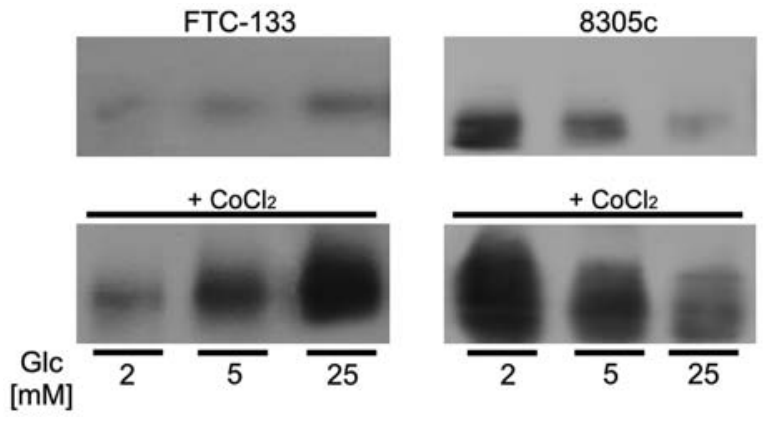

Figure 2. Effect of hypoglycemia, normoglycemia and hyperglycemia on the level of GLUT1 in plasma membrane in normoxic and hypoxic conditions in FTC-133 and 8305c cells. GLUT1, glucose transporter 1.

expression of GLUT1, GLUT3 and HIF1 $\alpha$ were analyzed by western blotting (Fig. 1A and B). The results showed that the total GLUT1 expression in the two cell types was higher than that in GLUT3. Numerous immunoreactive bands were present in GLUT1 immunoblot analysis due to glycosylation of GLUT1. For FTC-133 the expression of HIF1 $\alpha$ was much higher in cells treated with cobalt chloride compared to cells growing under normoxic conditions. A significant increase in the level of this protein under normoxic and hypoxic conditions with the increasing glucose concentration was observed. GLUT1 expression was also higher in cells incubated with cobalt chloride compared to cells in normoxia. However, the expression of this protein did not exhibit a positive correlation with glucose concentration. GLUT3 expression was higher in cells treated with $25 \mathrm{mM}$ glucose compared to cells grown in hypoglycemia or normoglycemia. HIF1 $\alpha$ expression in $8305 \mathrm{c}$ cells under normoxic conditions was undetectable. The cobalt chloride treatment caused an increase in the expression of this protein, however, in contrast to FTC-133 cells, the expression was inversely correlated with glucose concentration. The expression of GLUT1 also decreased with the increasing glucose concentration in the media. No difference in the expression of GLUT3 was detected.

The cell lines used in the present study showed significant differences in the level of total GLUT1 expression, which is particularly evident in the hypoxic conditions. FTC-133 showed a much higher expression of GLUT1 than that in 8305 c cells (Fig. 1C).

To estimate the plasma membrane level of GLUT1 the surface protein fractions of cells treated with different glucose concentration for $48 \mathrm{~h}$ were isolated. Western blot analyses showed that in FTC-133 cells plasma membrane GLUT1 expression increased with the increasing glucose concentration. The opposite results were obtained for $8305 \mathrm{c}$ cells, in which GLUT1 level in plasma membrane decreased with the increasing glucose level (Fig. 2). The plasma membrane expression levels of GLUT1 in the two cell types were correlated with the expression of HIF1 $\alpha$.

Glucose-dependent changes in AKT1 phosphorylation. In cells growing in hypoglycemia, normoglycemia and hyperglycemia for $48 \mathrm{~h}$, the expression and phosphorylation of AKT1 were analyzed (Fig. 3). The results showed that in FTC-133 and $8305 \mathrm{c}, \mathrm{AKT} 1$ expression was unchanged in all the glucose 
A
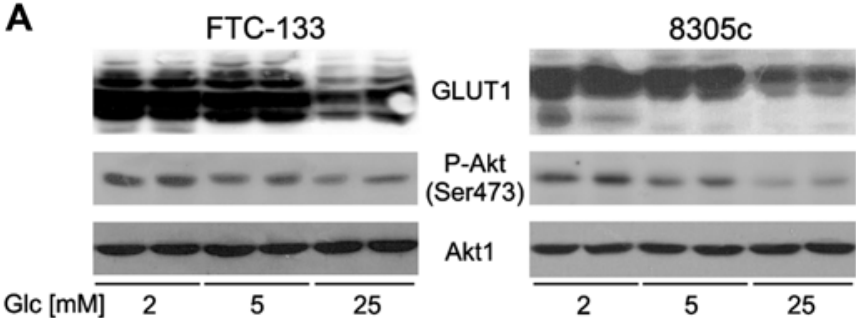

B

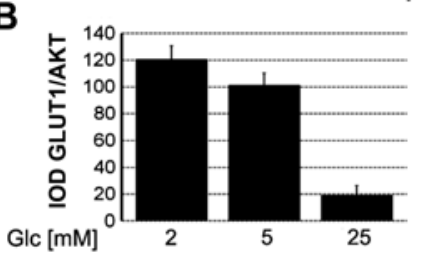

FTC-133

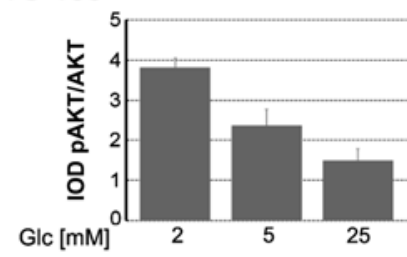

$8305 c$

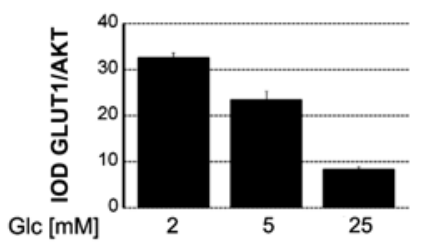

Figure 3. (A) Reduced expression of GLUT1 in FTC-133 and 8305c cells growing in hyperglycemia is correlated with reduced phosphorylation of Ser473 AKT1. (B) The intensity of the bands was analyzed by densitometry. GLUT1, glucose transporter 1 .
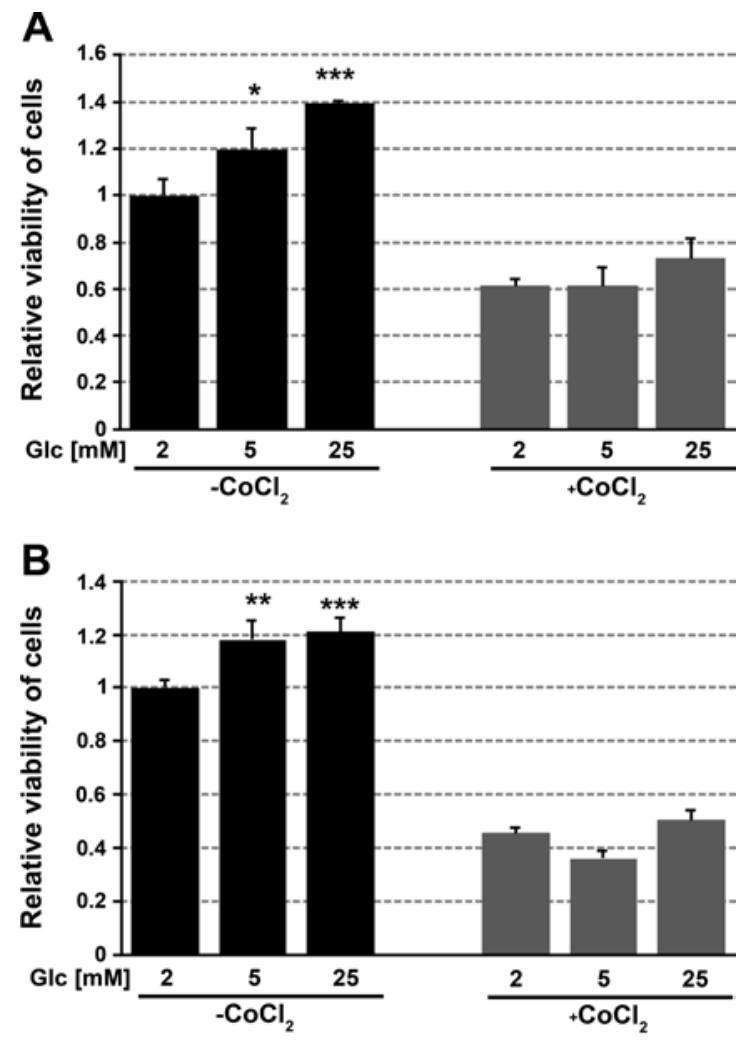

Figure 4. Effect of hypoglycemia, normoglycemia and hyperglycemia on viability of (A) FTC-133 and (B) 8305c cells. Data are presented as the average of at least three independent experiments $( \pm \mathrm{SD}){ }^{*} \mathrm{P}<0.05,{ }^{* * *} \mathrm{P}<0.01$ and ${ }^{* * *} \mathrm{P}<0.001$.
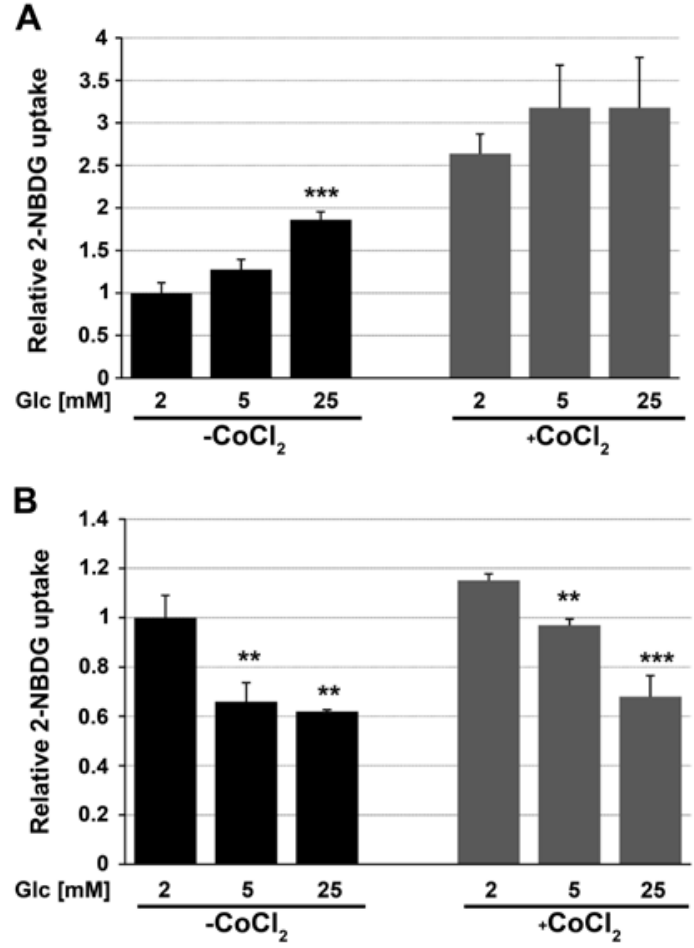

Figure 5. Glucose analog 2-NBDG uptake to (A) FTC-133 and (B) 8305c cells in hypoglycemia, normoglycemia and hyperglycemia. Data are presented as the average of at least three independent experiments performed in triplicate $( \pm \mathrm{SD}){ }^{*} \mathrm{P}<0.05,{ }^{* *} \mathrm{P}<0.01$ and ${ }^{* * *} \mathrm{P}<0.001$.

conditions but phosphorylation of Ser473 was higher in cells growing in low-glucose medium compared to cells in hyperglycemia. Glucose-dependent changes in AKT1 phosphorylation were correlated with total GLUT1 expression.

Impact of glucose concentration in medium on cell viability and glucose analog uptake. Viability of cells growing for $48 \mathrm{~h}$ in medium containing 2, 5 or $25 \mathrm{mM}$ glucose in normoxia or hypoxia was assessed using the MTT assay. The viability of cells growing in chemically induced hypoxia, i.e., in medium containing cobalt chloride was significantly lower compared with cells growing in normoxia. For FTC-133 and 8305c cells growing in normoxia, the increase in viability (20-40\%) was correlated with an increase in glucose concentration. There was no impact of glucose concentration on the viability of cells growing in hypoxic conditions (Fig. 4).

The 2-NBDG uptake of cells growing in hypoglycemia, normoglycemia and hyperglycemia for $48 \mathrm{~h}$ was quantified by flow cytometry (Fig. 5). FTC-133 cells growing in hyperglycemic conditions showed greater 2-NBDG uptake level than cells growing in medium with low-glucose concentration. The opposite results were obtained for $8305 \mathrm{c}$ cells. A significant decrease in the glucose uptake level was observed in cells growing in high glucose compared to ones in low glucose.

Impact of GLUT1 downregulation on cell viability and glucose analog uptake. To determine whether the observed changes in cell viability and glucose uptake are associated with GLUT1, the expression of GLUT1 was downregulated using siRNA. The control cells were transfected with a non-silent scrambled RNA duplex. The effect of RNAi was assessed by RT-PCR 
A

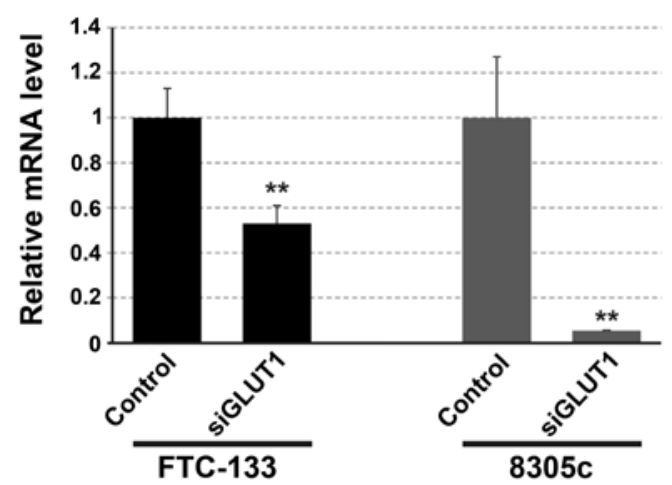

B
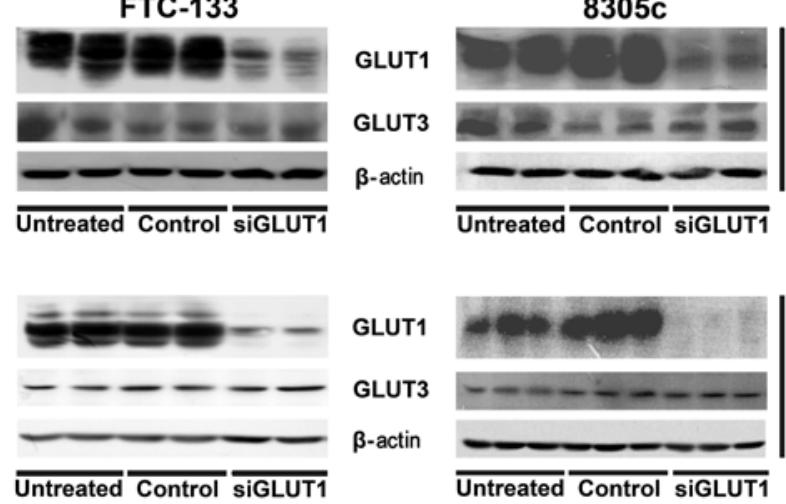

C

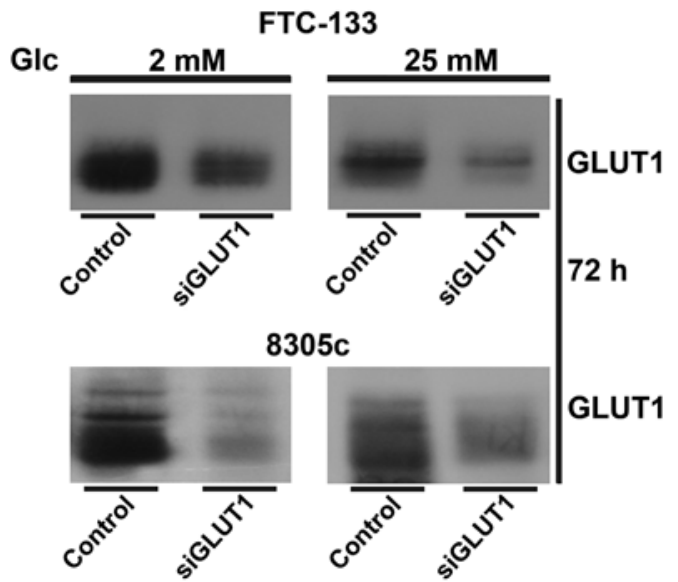

Figure 6. (A) GLUT1 mRNA, (B) total protein and (C) membrane expression levels in FTC-133 and 8305c cells 48 or $72 \mathrm{~h}$ after siRNA treatment. GLUT1, glucose transporter 1.

and western blotting after 48 or $72 \mathrm{~h}$. siRNA treatment caused a significant decrease in the mRNA and protein levels (Fig. 6). After $72 \mathrm{~h}$ the total protein level was reduced by $90 \%$ in the two types of thyroid cancer cells (Fig. 6B). A significant decrease of the GLUT1 level in the cell membrane was also observed (Fig. 6C). There was no effect of GLUT1 interference on GLUT3 expression.

The viability of control cells and cells treated with siRNA for $72 \mathrm{~h}$ was analyzed. There was no significant impact of GLUT1 downregulation on the viability of FTC-133 cells growing in hypoglycemia, normoglycemia or hyperglycemia (Fig. 7A). Cells $(8305 \mathrm{c})$ treated with siRNA and growing in normoxic conditions irrespective of the glucose concentration showed decreased cell viability and proliferation by $\sim 20 \%$ (Fig. 7B).
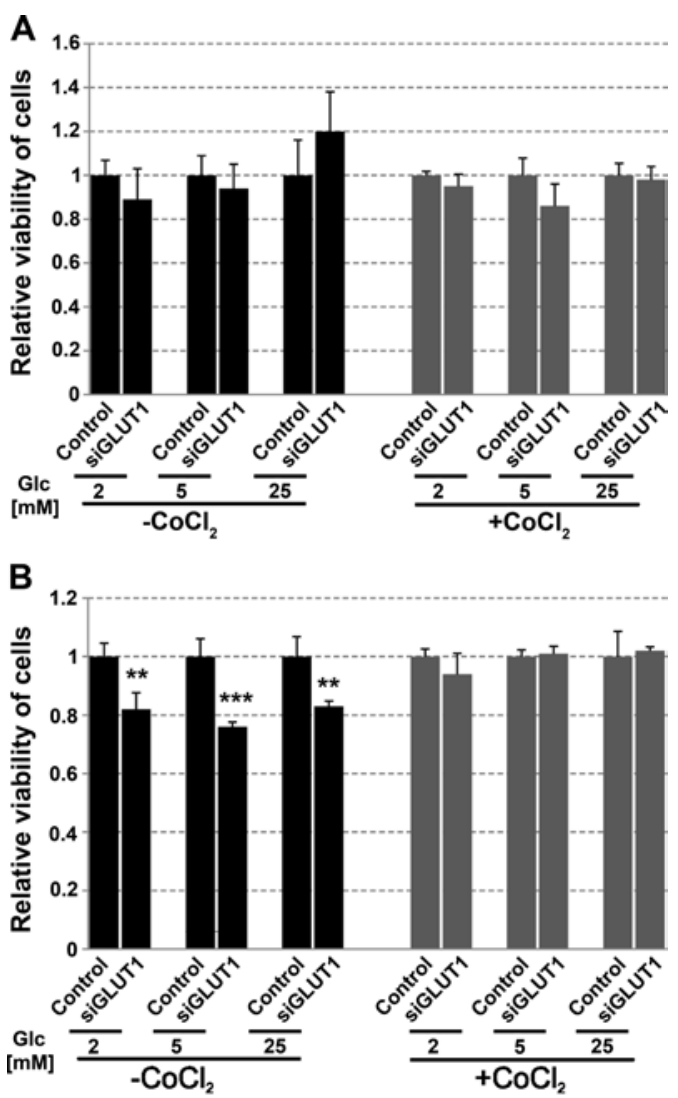

Figure 7. Effect of GLUT1 expression downregulation on (A) FTC-133 and (B) $8305 \mathrm{c}$ cell viability. Data are presented as the average of at least three independent experiments performed in triplicate $( \pm \mathrm{SD}){ }^{*} \mathrm{P}<0.05,{ }^{* *} \mathrm{P}<0.01$ and ${ }^{* * *} \mathrm{P}<0.001$. GLUT1, glucose transporter 1 .
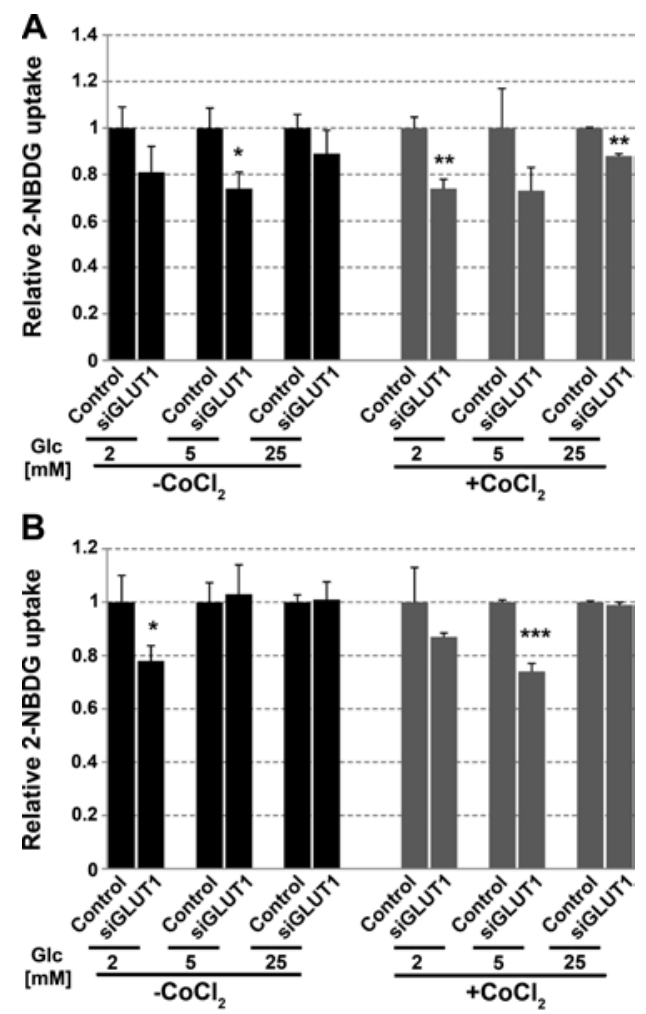

Figure 8. Effect of GLUT1 expression downregulation on glucose analog 2-NBDG uptake to (A) FTC-133 and (B) 8305c cells. Data are presented as the average of at least three independent experiments performed in triplicate $( \pm \mathrm{SD}){ }^{*} \mathrm{P}<0.05,{ }^{* * *} \mathrm{P}<0.01$ and ${ }^{* * *} \mathrm{P}<0.001$. GLUT1, glucose transporter 1 . 
However, GLUT1 downregulation did not affect the viability of cells growing in hypoxia conditions.

In FTC-133 cells, a reduced expression of GLUT1 caused marked changes in 2-NBDG uptake in normoxia and hypoxia (Fig. 8A). GLUT1 may have a greater impact on glucose uptake in low than in high glucose. For $8305 \mathrm{c}$ cells reduced glucose uptake has been observed mainly in low-glucose concentration (Fig. 8B).

\section{Discussion}

The impact of GLUT1 on glucose uptake and on the viability of FTC-133 and 8305c thyroid cancer cells growing in hypoglycemia, normoglycemia and hyperglycemia was analyzed. The total expression of GLUT1 in FTC-133 and 8305c cells was highest in cells growing in hypoglycemic conditions and lowest in hyperglycemic conditions. This result suggests that GLUT1 is a stress-responsive factor when glucose is limited. An association between the level of GLUT1 or GLUT3 expression and HIF-1 has been identified (27-33). This factor also induces the transcription of genes involved in glycolysis and causes an increase in the glucose metabolic rate (17). Our results show an opposite effect of glucose concentration on HIF1 $\alpha$ expression in the studied cell types. In FTC-133 cells in normoxia and hypoxia an increase in HIF1 $\alpha$ expression with an increase in glucose concentration was observed. The expression of HIF1 $\alpha$ as well as GLUT1 was higher in hypoxic condition compared to normoxia, which is consistent with previous studies $(27,29)$. However, no correlation was identified between glucose-dependent total GLUT1 and HIF1 $\alpha$ expression. This suggests that glucose concentration affected GLUT1 expression irrespective to that of HIF1. Previous data have shown that HIF1 $\alpha$ is not always correlated with glucose uptake. Bos et al (34) have shown that HIF1 $\alpha$ levels did not correlate well with increased (18) fluorodeoxyglucose (FdG) uptake measured by positron emission tomography in breast cancer. Yun et al (20) showed that the increased GLUT1 transcription in colorectal cancer cells was unrelated to HIF1 $\alpha$ since genetic disruption of the HIFlA gene did not affect the expression of GLUT1, or survival under hypoglycemic conditions. There are several possible mechanisms of GLUT1 expression regulation. Some oncogenes or suppressor proteins, including Ras, Raf, Myc, Src and p53 have been known to promote glucose uptake and metabolism as well as induce the transcription of GLUT1 (20,35-37). A serine/threonine kinase AKT is also one of the major factors involved in the stimulation of glucose transport and aerobic glycolysis in cancer cells (38). Activation of AKT is commonly observed in cancer cells, including thyroid cancer (39). AKT is a key mediator of cancer cell survival (40). Gao et al (41) demonstrated that in cancer cells transient glucose deprivation induces AKT phosphorylation at Thr308 and Ser473. However, in ovarian cancer, cells with constitutive activation of AKT glucose deprivation resulted in the activation of AMPK and inhibition of AKT phosphorylation (42). Our results have shown that AKT1 phosphorylation in FTC-133 and 8305c cells is dependent on the glucose concentration, i.e., it is the highest in hypoglycemic conditions and the lowest in hyperglycemia, which is consistent with GLUT1 total expression. This finding suggests that GLUT1 overexpression may be part of the AKT1-dependent mechanism allowing cells to survive in low glucose. Alternatively, high glucose may reduce AKT signaling in cells, resulting in a lower expression of GLUT1.

Although glucose-dependent GLUT1 total expression is not correlated with HIF1 $\alpha$ expression, the membrane level of this glucose transporter seems to be regulated by HIF1 $\alpha$. In both cell types the level of GLUT1 in plasma membrane was correlated with the expression of HIF $1 \alpha$ and with the glucose uptake level. However, the glucose concentration had an inverse effect on the expression of HIF1 $\alpha$ and GLUT1 as well as glucose uptake in FTC-133 and 8305c cells. Currently, we cannot explain the reason for the different effects of hypoglycemia, normoglycemia and hyperglycemia on FTC-133 and 8305 c cells.

Viability of cells grown for $48 \mathrm{~h}$ in low glucose was lower by 40 or $20 \%$ for FTC-133 and 8305 c cells, respectively, compared to cells grown in hyperglycemic conditions, which may support the hypothesis that high-glucose concentration is favorable for cancer development and progression. The results of Mathews et al (43) concerning the effect of glucose concentration on survival of HeLa cells showed that a reduction of glucose level from 6 to $3 \mathrm{mM}$ reduced cancer cell survival by $>30 \%$ only after $4 \mathrm{~h}$ exposure. However, those authors significantly reduced the concentration of glutamine levels, which is the second most important nutrient compound for cancer cells. Thus, a strong impact on cell survival resulted from combining glucose and glutamine starvation.

It has been shown that a reduced expression of GLUT1 affects cell growth and proliferation in a similar manner to glucose starvation. Young et al (44) have reported that reducing GLUT1 expression in mouse mammary tumor cell lines using shRNA reduced glucose transport and growth of cells. Li et al (45) found that GLUT1 overexpression promoted the cell viability of head and neck carcinoma cells whereas GLUT1 silencing had the opposite effect. On the other hand, in ovarian cancer cells sensitivity to glucose deprivation is independent of GLUT1 expression, growth rate or the rate of glucose uptake (42).

The main issue raised in our study was whether GLUT1 affected glucose uptake and viability of thyroid cancer cells. To address this issue, we used RNA interference to reduce the expression of GLUT1. The results showed that downregulation of GLUT1 expression in FTC-133 cells reduced 2-NBDG uptake by $20-25 \%$, yet did not significantly affect cell viability. These results are convergent to the results of Young et al (44) who showed that in some mouse mammary tumor cells the overexpression of GLUT1 increased glucose transport without increasing proliferation. However, since RNAi significantly reduced but did not eliminate GLUT1 expression in FTC-133 cells we cannot exclude the possibility that the remaining amount of protein is sufficient to transport enough glucose for cell survival. For $8305 \mathrm{c}$ cell reduction of GLUT1 expression by RNAi caused a decrease in cell viability by $\sim 20 \%$ but only in normoxic conditions. In 8305 c cells growing in normoxia the expression of GLUT1 was much lower compared to FTC-133, while RNAi almost completely eliminated this protein. However, glucose uptake was affected only in cells growing in low glucose.

Taken together our results suggest that the extent of GLUT1 impact on glucose uptake and cell viability may be 
cell-type-dependent. GLUT1 overexpression in low glucose suggests that GLUT1 is a universal stress responsive factor when glucose is limited. The effect of glucose concentration on GLUT1 expression and the fact that cancer cells are addicted to glucose render GLUT1 a promising therapeutic target. However, we suggest that strategies targeting GLUT1 alone may not be sufficient to reduce thyroid cancer cell viability. On the other hand GLUT1 may be considered a useful target in combination with other molecules that regulate tumor metabolism, such as certain oncogenes.

\section{Acknowledgements}

This study was supported by statutory funds for the Department of Cytobiochemistry, University of Lodz.

\section{References}

1. Dang CV: Links between metabolism and cancer. Genes Dev 26: 877-890, 2012

2. Bensinger SJ and Christofk HR: New aspects of the Warburg effect in cancer cell biology. Semin Cell Dev Biol 23: 352-361, 2012.

3. Graham NA, Tahmasian M, Kohli B, Komisopoulou E, Zhu M, Vivanco I, Teitell MA, Wu H, Ribas A, Lo RS, Mellinghoff IK, Mischel PS and Graeber TG: Glucose deprivation activates a metabolic and signaling amplification loop leading to cell death. Mol Syst Biol 8: 589, 2012.

4. Palorini R, Cammarata FP, Balestrieri C, Monestiroli A, Vasso M, Gelfi C, Alberghina L and Chiaradonna F: Glucose starvation induces cell death in K-ras-transformed cells by interfering with the hexosamine biosynthesis pathway and activating the unfolded protein response. Cell Death Dis 4: e732, 2013.

5. Mendivil-Perez M, Jimenez-Del-Rio $M$ and Velez-Pardo C: Glucose starvation induces apoptosis in a model of acute $\mathrm{T}$ leukemia dependent on caspase-3 and apoptosis-inducing factor: a therapeutic strategy. Nutr Cancer 65: 99-109, 2013.

6. Ganapathy V, Thangaraju M and Prasad PD: Nutrient transporters in cancer: relevance to Warburg hypothesis and beyond. Pharmacol Ther 121: 29-40, 2009.

7. Adekola K, Rosen ST and Shanmugam M: Glucose transporters in cancer metabolism. Curr Opin Oncol 24: 650-654, 2012.

8. Jóźwiak P and Lipińska A: The role of glucose transporter 1 (GLUT1) in the diagnosis and therapy of tumors. Postepy Hig Med Dosw 66: 165-174, 2012 (In Polish).

9. Szablewski L: Expression of glucose transporters in cancers. Biochim Biophys Acta 1835: 164-169, 2013.

10. Calvo MB, Figueroa A, Pulido EG, Campelo RG and Aparicio LA: Potential role of sugar transporters in cancer and their relationship with anticancer therapy. Int J Endocrinol 2010: pii: 205357, 2010. doi: 10.1155/2010/205357.

11. Mori Y, Tsukinoki K, Yasuda M, Miyazawa M, Kaneko A and Watanabe Y: Glucose transporter type 1 expression are associated with poor prognosis in patients with salivary gland tumors. Oral Oncol 43: 563-569, 2007.

12. Chung FY, Huang MY, Yeh CS, Chang HJ, Cheng TL, Yen LC, Wang JY and Lin SR: GLUT1 gene is a potential hypoxic marker in colorectal cancer patients. BMC Cancer 9: 241, 2009.

13. Krzeslak A, Wojcik-Krowiranda K, Forma E, Jozwiak P, Romanowicz H, Bienkiewicz A and Brys M: Expression of GLUT1 and GLUT3 glucose transporters in endometrial and breast cancers. Pathol Oncol Res 18: 721-728, 2012.

14. Sasaki H, Shitara M, Yokota K, Hikosaka Y, Moriyama S, Yano M and Fujii Y: Overexpression of GLUT1 correlates with Kras mutations in lung carcinomas. Mol Med Rep 5: 599-602, 2012.

15. Cho H, Lee YS, Kim J, Chung JY and Kim JH: Overexpression of glucose transporter-1 (GLUT-1) predicts poor prognosis in epithelial ovarian cancer. Cancer Invest 31: 607-615, 2013.

16. Jóźwiak P, Krześlak A, Pomorski L and Lipińska A: Expression of hypoxia-related glucose transporters GLUT1 and GLUT3 in benign, malignant and non-neoplastic thyroid lesions. Mol Med Rep 6: 601-606, 2012.
17. Monti E and Gariboldi MB: HIF-1 as a target for cancer chemotherapy, chemosensitization and chemoprevention. Curr Mol Pharmacol 14: 62-77, 2011.

18. Mills KT, Bellows CF, Hoffman AE, Kelly TN and Gagliardi G: Diabetes mellitus and colorectal cancer prognosis: a metaanalysis. Colon Rectum Dis 56: 1304-1319, 2013.

19. Zhu Z, Wang X, Shen Z, Lu Y, Zhong S and Xu C: Risk of bladder cancer in patients with diabetes mellitus: an updated meta-analysis of 36 observational studies. BMC Cancer 13: 310 , 2013.

20. Yun J, Rago C, Cheong I, Pagliarini R, Angenendt $\mathrm{P}$, Rajagopalan H, Schmidt K, Willson JK, Markowitz S, Zhou S, Diaz LA, Velculescu VE, Lengauer C, Kinzler, KW, Vogelstein B and Papadopoulos N: Glucose deprivation contributes to the development of KRAS pathway mutations in tumor cells. Science 325: 1555-1559, 2009.

21. Andersen DK: Diabetes and cancer: placing the association in perspective. Curr Opin Endocrinol Diabetes Obes 20: 81-86, 2013. doi: 10.1155/2013/291546.

22. Shikata K, Ninomiya T and Kiyohara Y: Diabetes mellitus and cancer risk: review of the epidemiological evidence. Cancer Sci 104: 9-14, 2013.

23. De Pergola G and Silvestris F: Obesity as a major risk factor for cancer. J Obes 2013: 291546, 2013.

24. Li W, Ma Q, Liu J, Han L, Ma G, Liu H, Shan T, Xie K and Wu E: Hyperglycemia as a mechanism of pancreatic cancer metastasis. Front Biosci 17: 1761-1774, 2012.

25. Shih SR, Chiu WY, Chang TC and Tseng CH: Diabetes and thyroid cancer risk: literature review. Exp Diabetes Res 2012: 578285,2012

26. Yamada K, Saito M, Matsuoka $\mathrm{H}$ and Inagaki N: A real-time method of imaging glucose uptake in single, living mammalian cells. Nat Protoc 2: 753-762, 2007.

27. Ren BF, Deng LF, Wang J, Zhu YP, Wei L and Zhou Q: Hypoxia regulation of facilitated glucose transporter-1 and glucose transporter-3 in mouse chondrocytes mediated by HIF-1 $\alpha$. Joint Bone Spine 75: 176-181, 2008.

28. Lidgren A, Bergh A, Grankvist K, Rasmuson T and Ljungberg B Glucose transporter-1 expression in renal cell carcinoma and its correlation with hypoxia inducible factor-1 $1 \alpha$. BJU Int 101: 480-484, 2008.

29. Baumann MU, Zamudio S and Illsley NP: Hypoxic upregulation of glucose transporters in BeWo choriocarcinoma cells is mediated by hypoxia-inducible factor- 1 . Am J Physiol Cell Physiol 293: C477-C485, 2007.

30. Iida T, Yasuda M, Miyazawa M, Fujita M, Osamura RY, Hirasawa T, Muramatsu T, Murakami M, Saito K and Mikami M: Hypoxic status in ovarian serous and mucinous tumors: relationship between histological characteristics and HIF-1 $\alpha /$ GLUT-1 expression. Arch Gynecol Obstet 277: 539-546, 2008.

31. Yasuda M,Miyazawa M,Fujita M, Kajiwara H,Iida T, Hirasawa T, Muramatsu T, Murakami M, Mikami M, Saitoh K, Shimizu M, Takekoshi S and Osamura RY: Expression of hypoxia inducible factor-1 $\alpha$ (HIF-1 $\alpha)$ and glucose transporter-1 (GLUT-1) in ovarian adenocarcinomas: Difference in hypoxic status depending on histological character. Oncol Rep 19: 111-116, 2008.

32. Liu Y, Li YM, Tian RF, Liu WP, Fei Z, Long QF, Wang XA and Zhang X: The expression and significance of HIF-1 $\alpha$ and GLUT-3 in glioma. Brain Res 1304: 149-154, 2009.

33. Wu XH, Chen SP, Mao JY, Ji XX, Yao HT and Zhou SH: Expression and significance of hypoxia-inducible factor- $1 \alpha$ and glucose transporter-1 in laryngeal carcinoma. Oncol Lett 5: 261-266, 2013.

34. Bos R, van Der Hoeven JJ, van Der Wall E, van Der Groep P, van Diest PJ, Comans EF, Joshi U, Semenza GL, Hoekstra OS, Lammertsma AA and Molthoff CF: Biologic correlates of ${ }^{18}$ fluorodeoxyglucose uptake in human breast cancer measured by positron emission tomography. J Clin Oncol 20: 379-387, 2002.

35. Flier JS, Mueckler MM, Usher P and Lodish HF: Elevated levels of glucose transport and transporter messenger RNA are induced by ras or src oncogenes. Science 235: 1492-1495, 1987.

36. Osthus RC, Shim H, Kim S, Li Q, Reddy R, Mukherjee M, Xu Y, Wonsey D, Lee, LA and Dang CV: Deregulation of glucose transporter 1 and glycolytic gene expression by c-Myc. J Biol Chem 275: 21797-21800, 2000.

37. Zhang C, Liu J, Liang Y, Wu R, Zhao Y, Hong X, Lin M, Yu H, Liu L, Levine AJ, Hu W and Feng Z: Tumour-associated mutant p53 drives the Warburg effect. Nat Commun 4: 2935, 2013. 
38. Elstrom RL, Bauer DE, Buzzai M, Karnauskas R, Harris MH, Plas DR, Zhuang H, Cinalli RM, Alavi A, Rudin CM and Thompson CB: Akt stimulates aerobic glycolysis in cancer cells. Cancer Res 64: 3892-3899, 2004.

39. Viglietto G, Amodio N, Malanga D, Scrima M and De Marco C: Contribution of $\mathrm{PKB} / \mathrm{AKT}$ signaling to thyroid cancer. Front Biosci 16: 1461-1487, 2011.

40. Cassinelli G, Zuco V, Gatti L, Lanzi C, Zaffaroni N, Colombo D and Perego P: Targeting the Akt kinase to modulate survival, invasiveness and drug resistance of cancer cells. Curr Med Chem 20: 1923-1945, 2013.

41. Gao M, Liang J, Lu Y, Guo H, German P, Bai S, Jonasch E, Yang X, Mills GB and Ding Z: Site-specific activation of AKT protects cells from death induced by glucose deprivation. Oncogene 33: 745-755, 2014.

42. Priebe A, Tan L, Wahl H, Kueck A, He G, Kwok R, Opipari A and Liu JR: Glucose deprivation activates AMPK and induces cell death through modulation of Akt in ovarian cancer cells. Gynecol Oncol 122: 389-395, 2011.
43. Mathews EH, Stander BA, Joubert AM and Liebenberg L: Tumor cell culture survival following glucose and glutamine deprivation at typical physiological concentrations. Nutrition 30: 218-227, 2014.

44. Young CD, Lewis AS, Rudolph MC, Ruehle MD, Jackman MR, Yun UJ, Ilkun O, Pereira R, Abel ED and Anderson SM: Modulation of glucose transporter 1 (GLUT1) expression levels alters mouse mammary tumor cell growth in vitro and in vivo. PLoS One 6: e23205, 2011.

45. Li S, Yang X, Wang P and Ran X: The effects of GLUT1 on the survival of head and neck squamous cell carcinoma. Cell Physiol Biochem 32: 624-634, 2013. 